\title{
Platform heterogeneity, platform governance and complementors' product performance: an empirical study of the mobile application industry
}

\author{
Jingtao $\mathrm{Yi}^{1}$, Jinqiu $\mathrm{He}^{1 *}$ and Lihong $\mathrm{Yang}^{2}$
}

\footnotetext{
*Correspondence: hismarck@163. com

${ }^{1}$ Business School, Renmin University of China, Beijing 100872, China Full list of author information is available at the end of the article
}

\begin{abstract}
The platform economy is becoming an important engine for industrial innovation and economic growth. However, empirical research on how platform governance affects product performance through network externalities remains limited. Leveraging the perspective of platform ecosystems, this paper intends to empirically investigate the impact of platform governance on the product performance of complementors in the mobile application industry, based on firstly released apps on Apple's App Store and Google Play. Our study shows that complementors of free mobile applications on the weakly regulated platform, Google Play, perform much better than those on the strictly regulated platform, Apple's App Store, due to the larger size of the installed base. However, complementors on the strictly regulated platform, Apple's App Store, can take advantage of highly valued end-users on the demand side and higher degrees of product differentiation on the supply side to enhance their product performance. This is likely due to higher entry barriers for complementors, and better user communities for end-users. We suggest that higher competition efficiency and performance levels are linked to the platforms associated with strict governance.

Keywords: Platform heterogeneity, Network externality, Platform governance, Complementor's product performance, Competition, Product differentiation, Digital technology
\end{abstract}

\section{Introduction}

Over the past few decades, the revolution in information and digital technologies has been reshaping the global business environment. There are large numbers of digital platforms in different industries. Platform owners and their complementors provide end-consumers with a variety of services or products. Gawer and Cusumano (2014) classify digital platforms into two forms according to the properties of service or product suppliers on the platforms: internal or company-specific platforms and external or industry-wide platforms. Gawer (2014) further defines industry platforms which are governed by platform enterprises as complementary goods or services supplied by more enterprises. On the foundation of technical architectures, industry platforms orchestrate business ecosystems which encompass platform owners, platform providers, complementors and consumers (Adner and Kapoor 2010; Ceccagnoli et al. 2012;

(c) The Author(s). 2019 Open Access This article is distributed under the terms of the Creative Commons Attribution 4.0 International License (http://creativecommons.org/licenses/by/4.0/), which permits unrestricted use, distribution, and reproduction in any medium provided you give appropriate credit to the original author(s) and the source, provide a link to the Creative Commons license, and indicate if changes were made. 
Kapoor and Agarwal 2017; van Alstyne et al. 2016). As the leaders in digital innovations, technology firms such as Microsoft, Apple and Google have already developed their own digital platforms to set rules for all participants in platform ecosystems. In order to adapt to consumer preferences, complementors are granted technological interfaces and modular components by platform owners to develop, display and debug their digital products. Based on value-added innovations generated from the iterative interactions of complementors and end-users (i.e., network externalities), platform enterprises may promote a great leap for the platform ecosystems (Boudreau and Jeppesen 2015; Kapoor and Agarwal 2017; Yonatany 2017). Technical architectures, regulations and network externalities are increasingly transforming the way platform enterprises, complementors and end-users interact, as well as improving the growth and core competitiveness of platforms (Parker et al. 2016). ${ }^{1}$

Existing studies emphasize that platforms play the role of intermediaries in two-sided or multi-sided markets (e.g., Armstrong 2006; Rochet and Tirole 2003, 2006). However, platform enterprises find it difficult to adopt an effective and solid governance strategy to improve the two-sided matching efficiency through a platform-mediated network (Tiwana 2013; Tiwana et al. 2010). Based on network externalities, i.e., the number of end-users/complementors of the platform will increase/decrease when the value attached to the platform is higher/ lower, platform enterprises need to be very cautious when they set the rules for the platform ecosystem participants to make the whole platform grow (Cennamo and Santalo 2013). Quality concerns about products on platforms often arise from the process when platform governance is ineffective (Hagiu and Spulber 2013). For instance, the large quantities of fakes on Taobao and security issues arising from car-hailing platforms and short rental service platforms have garnered public attention in China and in the rest of the world.

Moreover, previous research on platform governance has assumed homogeneous platforms which do not completely account for the behavior of platform participants in the real world (e.g., Anderson and Coate 2005; Armstrong 2006; Cennamo and Santalo 2013; Gawer and Henderson 2007; Ghazawneh and Henfridsson 2013; Rochet and Tirole 2003, 2006). As Gawer (2014) suggests, the combination of the perspectives of economic theory and engineering design will help clarify how platforms operate in reality. Existing studies which focus on platform heterogeneity incorporate the view of engineering design to classify digital platforms into proprietary platforms and open source platforms (e.g., Boudreau 2010; Cheng and Liu 2012; Economides and Katsamakas 2006; West 2003). Therefore, we intend to account for heterogeneous platform governance through the openness of operating systems. Digital platforms can control the platform through proprietary techniques or totally grant access to independent complementors, which implies heterogeneous platform governance strategies (Boudreau 2010). Therefore, we classify heterogeneous digital platforms into strictly regulated platforms and weakly regulated platforms. Leveraging a sample of two heterogeneous mobile application platforms, Apple's App Store and Google Play where complementors' competition and innovation are heavily reliant on the differentiated technical architectures of the platforms, our study intends to analyze heterogeneous platform governance strategies and their impacts on complementors' product performance to cultivate the growth of the platform ecosystem.

Different from other types of platforms, technological industry platforms only charge the developers (i.e., complementors) a fixed fee and share a fixed proportion of the 
revenue that developers make from their own end-users. ${ }^{2}$ Faced with intense competition, many developers on technological platforms supply end-users with free digital products so as to enlarge the size of the installed base and hence quickly break into the market. Free digital product developers set in-app purchase choices and seek to cooperate with external partners (i.e., advertising, organizing online activities and collecting data through their digital products) to yield profits (Carare 2012; Garg and Telang 2013; Parker and van Alstyne 2005).

In the case of mobile application industry platforms, $90 \%$ of downloads from the two major mobile application markets, Apple's App Store and Google Play, are free. ${ }^{3}$ Apple's App Store, with a closed, proprietary operating system, sets strict rules to govern complementors' use of the platform, while Google Play's rules appear more flexible owing to its open operating system. We argue that different platform governance strategies influence the ways in which platform enterprises leverage network externalities. Google Play regulates its platform ecosystem flexibly to take advantage of the size effect of network externalities, while Apple's App Store regulates its platform ecosystem strictly to take advantage of the quality effect of network externalities.

Although the business strategies of Apple's App Store and Google Play are different, to what extent they help complementors leverage network externalities and enhance competitive advantages of the two heterogeneous platforms remains underexplored (Armstrong 2006; Caillaud and Jullien 2003; Hagiu 2006; Rochet and Tirole 2003; Weyl 2010). Emphasizing platform enterprises' governance strategies and network externalities, we elucidate the economic behavior and dynamic interactive mechanism of platform complementors and end-users, yielding new insights into the governance strategies and network externalities of heterogeneous platforms. We further explore how platform governance drives the network externalities and complementors' performance on heterogeneous platforms using free digital products' micro-level data.

Our study makes three contributions. First, we enhance the understanding of the impacts of platform governance on network externalities from the perspective of platform ecosystems. Our study elucidates how platform enterprises govern the whole platform ecosystem through technological standards and how value is created and flows through iterative interactions between platform ecosystem participants by embedding all components in the relationship networks based on technical architectures.

Second, our study sheds light on the role of platform heterogeneity arising from platform governance strategies. Previous research on two-sided or multi-sided markets have always been limited to homogeneous platforms or a single platform, but knowledge about how platform heterogeneity affects platform participants' strategies and behavior is limited. Our study enriches the analyses of network externalities on heterogeneous digital platforms by utilizing platform-level and application-level data from Apple's App Store and Google Play.

Third, we further demonstrate how platform complementors respond to and benefit from platform governance strategies by making use of the network externalities efficiently. Due to the degree of openness of platforms, complementors may set different pricing and innovative strategies to attract end-users (Bhargava and Choudhary 2008). Our study quantifies how free digital products' performance is driven by business models and the innovation strategies of complementors on heterogeneous platforms, which enriches the empirical analyses of business strategies of complementors on heterogeneous platforms. 


\section{Theoretical framework and hypotheses}

\section{Setup}

Based on Rochet and Tirole (2003, 2006), we define the digital platforms as the twosided markets or intermediate platforms which charge supplier and consumer groups a fixed entry price on a lump-sum basis. In addition, both groups can exert externalities on each other (Armstrong 2006). We build a theoretical model to explain the determinants of free digital products' performance on technological platforms. We denote the group of consumers as group-1 and the group of suppliers as group- 2 .

Suppose there are $n_{1}^{i}$ members in group- 1 on platform $i$ and they are willing to pay for the product at a price of no more than $\alpha_{1}^{i}$ (that means consumers will buy the product when its price is $\left.P_{1}^{i} \leq \alpha_{1}^{i}\right)$. Then we define $P_{2}^{i}$ as the platform's price to group- 2 and $b_{2}^{i}$ as the platform's entry barriers (i.e., sunk costs, including the expenses on dedicated devices, research and development, etc.). If a developer in group-2 wants to launch its digital products on platform $i$, it needs to pay $T_{2}^{i}=P_{2}^{i}+b_{2}^{i}$. For each supplier in group-2, the unknown $\alpha_{2}^{i}$ measures the benefit it gets from every end-user. The discounted factor $v^{i}$ measures the discounted future returns of the free digital product based on its technological level, diverse revenue models and expectations of the industry. When $\frac{\alpha_{2}^{i}}{v^{i}} n_{1}^{i} \geq T_{2}^{i}$, the platform complementor will enter the platform. We define $\alpha_{2}^{i}$ as independently and identically drawn from a distribution function $F\left(\alpha_{2}^{i}\right)$. Additionally, $F\left(\alpha_{2}^{i}\right)$ is an increasing function of $\alpha_{2}^{i}$. Therefore, the function $\phi^{i}$ which defines the size $n_{2}^{i}$ of members in group-2 is as follow:

$$
\phi^{i}\left(n_{1}^{i}, v^{i}, T_{2}^{i}\right)=1-F\left(v^{i} T_{2}^{i} / n_{1}^{i}\right)=1-F\left\{v^{i}\left(P_{2}^{i}+b_{2}^{i}\right) / n_{1}^{i}\right\}
$$

Equation (1) clarifies that the number of complementors on platform $i$ is decided by the discounted factor, entry price and other barriers, and the size of users.

\section{Entry cost and platform choice}

In order to enlarge the size of the installed base, technological platforms usually grant end-users access to digital products without charge and even provide subsidies. To simplify our theoretical model, we postulate each complementor on platform $i$ only produces one free digital product and the platform will share a proportion of the revenue it earns. The profits of platform $i$ are given as:

$$
\pi^{i}=R_{2}^{i}\left(\phi^{i}\right)+s \cdot p_{1}^{i}\left(c_{1}^{i}, \gamma_{1}^{i}, \phi^{i}\right) \cdot n_{1}^{i}-\left(F^{i}+f_{1}^{i} n_{1}^{i}+f_{2}^{i} n_{2}^{i}\right)
$$

where $R_{2}^{i}$ is platform $i$ 's entry cost and $p_{1}^{i}$ is the expected returns from each consumer for a unit product. $p_{1}^{i}$ is related to consumers' characteristic parameter $c_{1}^{i}$, the unit revenue $\gamma_{1}^{i}$ earned from ads or other online activities, and the size of complementors $\phi^{i}$ on platform $i . s$ is the fixed revenue proportion that platform $i$ shares which is set by the industry. $F^{i}$ is the fixed costs of platform $i$ 's daily operation while $f_{1}^{i}$ and $f_{2}^{i}$ are platform $i$ 's expenses for serving each end-user and complementor. The $p_{2}^{i}$ which maximizes $\pi^{i}$ is: 


$$
P_{2}^{i}=f_{2}^{i}-\frac{\partial P_{2}^{i}}{\partial n_{2}^{i}} n_{2}^{i}-s \cdot \frac{\partial p_{1}^{i}\left(c_{1}^{i}, \gamma_{1}^{i}, \phi^{i}\right)}{\partial n_{2}^{i}} n_{1}^{i}
$$

\section{Complementors' competition}

Given that consumers can download the digital product without charge, we suppose the size of product $j$ 's installed base on platform $i$ is $m_{j}^{i}, d_{j}$ is the dummy variable which measures whether the developer provides in-app purchase choices and $p_{j}^{i}$ is the price for in-app purchases. We propose the probability of $p_{j}^{i} \leq \alpha_{1}$ is $\delta^{i}\left(\theta^{i}\right)$, where $\delta^{i}$ is decided by the degree of product differentiation $\theta^{i}$ of complementors on platform $i$. The degree of product differentiation reflects the product diversity on platform $i$ and hence affects consumers' comments and willingness to pay. Considering complementors' revenues from external partners, we define the revenue function of each complementor as:

$$
R_{j}^{i}=\left(d_{j} \delta^{i}\left(\theta^{i}\right) p_{j}^{i}+\gamma_{1}^{i}\right) m_{j}^{i} .
$$

Then the profits of each complementor on platform $i$ are:

$$
\pi_{j}^{i}=\left\{\begin{array}{c}
\left(\delta^{i}\left(\theta^{i}\right) p_{j}^{i}+\gamma_{1}^{i}\right) m_{j}^{i}-\left(T_{2}^{i}+f_{j}^{i} m_{j}^{i}\right), \quad d_{j}=1 \\
\gamma_{1}^{i} m_{j}^{i}-\left(T_{2}^{i}+f_{j}^{i} m_{j}^{i}\right), \quad d_{j}=0
\end{array}\right.
$$

where $f_{j}^{i}$ is the cost for the free product developer to serve each end-user and $\gamma_{1}^{i}$ is given by external partners. Given the specification in equation (3), the revenue function of each complementor who chooses to set the in-app purchase choice is:

$$
R_{j}^{i}=\left(f_{j}^{i}-\delta^{i}\left(\theta^{i}\right) \frac{\partial p_{j}^{i}}{\partial m_{j}^{i}} m_{j}^{i}\right) m_{j}^{i}=\alpha_{j}^{i} m_{j}^{i} .
$$

Equations (3) and (4) suggest that each complementor's revenue is positively corelated with the size of the installed base regardless of the in-app purchase choice. If product differentiation and innovation speed can promote consumers' willingness to pay, free digital products' performance will be improved. Moreover, digital platforms' marginal costs of serving end-users are insignificant. To be more precise, $d_{j}$ depends on the market positioning of developers while $\theta^{i}$ depends on the business models of developers and governance strategies of platform enterprises on heterogeneous platforms, $n_{2}^{i}$, on platform $i$. According to equation (1), $n_{2}^{i}$ is given by the size consumers, $n_{1}^{i}$, attracted by platform $i$ based on its technological standards. Meanwhile, $m_{j}^{i}$ is restricted by $n_{1}^{i}$. $\alpha_{j}^{i}$ and $m_{j}^{i}$ will vary on heterogeneous digital platforms.

\section{Platform heterogeneity and network externalities}

Platform enterprises manipulate the matching process of platform complementors and end-users. The direct/indirect network effects and iterative interactions between platform complementors and end-users on platforms dominate the process of value creation (van Alstyne et al. 2016). As our theoretical model indicates, the size of the installed base plays a dominating role when complementors make an effort to improve their product performance by leveraging direct/indirect network effects, despite their different business strategies on heterogeneous platforms. 
The business model of free digital products heavily depends on the scale of the demand side. The direct network effects on the demand side, i.e., that the number of end-users will increase when the value attached to the group of end-users is higher, help platform complementors attain profit from economies of scale and the efficiency enhancement in demand aggregation (Gawer 2014; Parker and van Alstyne 2005). With the development of the Internet, platform enterprises and complementors can save the costs of resource allocation constrained by physical space-time and grant users free digital interfaces to expand the installed base (Feng and Chen 2016). Since weakly regulated platforms based on open operating systems set much lower entry barriers, the size of the installed base on such platforms is much larger than the one on strictly regulated platforms. Due to the competitive advantage of the larger size of the installed base, it is easier for complementors on weakly regulated platforms to earn more revenue relying on the size effect.

The governance of complementors on digital platforms mainly includes the control of complementors' accessibility and the whole input and output process (Benlian et al. 2015; Ghazawneh and Henfridsson 2013; Tiwana et al. 2010). Since the larger group of end-users is based on low transaction costs, complementors on weakly regulated platforms allow target customers to make use of the functions for free and directly take advantage of the size effect of network externalities. In contrast, complementors on strictly regulated platforms have to rely on the quality effect of network externalities to lock in the target customers who prefer high-quality products regardless of transaction costs. Due to the difference in the size of the installed base and target customers' sensitivity of transaction costs, complementors on weakly regulated platforms tend to strengthen the size effect from demand aggregation while those on strictly regulated platforms focus more on acquiring extra consumer surplus from end-users. However, consumers on weakly regulated platforms are prone to sacrifice some time/space (i.e., reading ads, doing questionnaires, and participating in online activities) to enjoy the functions of digital products without monetary costs. Therefore, for free digital products, the size effect can be significantly enhanced for complementors on weakly regulated platforms. The discussion leads to:

Hypothesis 1: Complementors of free digital products on strictly regulated platforms perform worse than those on weakly regulated platforms.

\section{The relationship networks in platform ecosystems and complementors' performance}

Based on platform resources, the iterative interactions due to network externalities between complementors, end-users, platform enterprises and external traders provide complementors with opportunities to innovate and attach more value to their digital products in the platform ecosystem (Adner and Kapoor 2010; Gawer and Cusumano 2014; Rochet and Tirole 2006). Complementors exploit network externalities differently on heterogeneous platforms due to consumer heterogeneity on the demand side and product differentiation on the supply side. Meanwhile, network externalities are the essential motives for platform growth (Gawer and Cusumano 2014). From the perspective of platform ecosystems, platform enterprises intend to implement effective governance strategies to cultivate positive interactions between platform ecosystem participants and thus promote the value creation of the whole ecosystem (Adner and Kapoor 2010; Cennamo and Santalo 2013; Kapoor and Lee 2013). 
Although open platforms can attract large quantities of complementors and accelerate the innovative speed of technologies and products, the lack of strict platform governance can cause devastating disorders inside the platform ecosystem (Gawer 2014; West 2003), including efficiency loss driven by business-stealing effects (i.e., product imitation and infringement) (Economides and Katsamakas 2006; Hagiu 2006). In view of platform envelopment strategy, the vertical integration of operating systems and terminal devices can help technological platform enterprises develop a closed technology chain and thus exert strict governance on the whole ecosystem (Eisenmann et al. 2011). This can enhance the quality of complementary products or services as well as the degree of differentiation, leading to higher competition efficiency. In the real world, video websites such as Youku, iQiyi, and LeTV, who have expanded their business in the field of TV boxes, and game platforms such as Microsoft's Xbox, Sony's Play Station and Nintedo, who have also expanded their business in the downstream console industry, spare no effort to capture their target customers by exploiting technology chains. Technical architecture substantially promotes the virtuous cycle of the components inside the platform ecosystem.

End-users also play an important role in product innovation and co-production. The value accruing to platform complementors arises from end-users' preferences and effective feedback (Katz and Shapiro 1985). Platform complementors need to develop good relationships with other participants in the platform ecosystem if they want to capture value from in-app purchases or from cooperating with external partners. Specifically, they should adjust the characteristics of digital products to match customers' preferences and pay attention to innovative strategies and competitive pressures on the supply side in order to maintain their core competitiveness. The relationship networks inside the platform ecosystem are shown in Fig. 1. The interactions between platform ecosystem participants are heavily reliant on the degree of platform openness. On account of the rigorous quality control system along the value chain, Apple indeed improves much the quality of products and services it offers.

\section{The heterogeneity in the consumer group}

Consumers pay for certain product or service to get value. The realization of consumers' personal values partly depends on the satisfaction of epistemic values (Sheth et al. 1991; Vinson et al. 1977).

Consumers' expectation of getting higher surplus value raises concerns over transaction costs and the value in use. Platform complementors have to unearth more value in end-users so as to create more added value and improve their performance. Free digital product developers exploit "threshold effects" to attract target customers, aiming at achieving better performance. They expect to satisfy the end-users' anticipating value at first and continuously explore the end-users' potential value, which will gradually lead to the improvement in customers' personal values. ${ }^{4}$ In diverse target market segments associated with technological characteristics, the levels of end-users' sensibility of value and transaction costs are different. Consumers who choose products on strictly regulated platforms are more concerned with added value. In practice, most users who choose high-quality digital products are well-educated employees in technologyintensive industries. They are quite sensitive and adaptable to information technology. They pay more attention to the functional design and spend more time on digital 


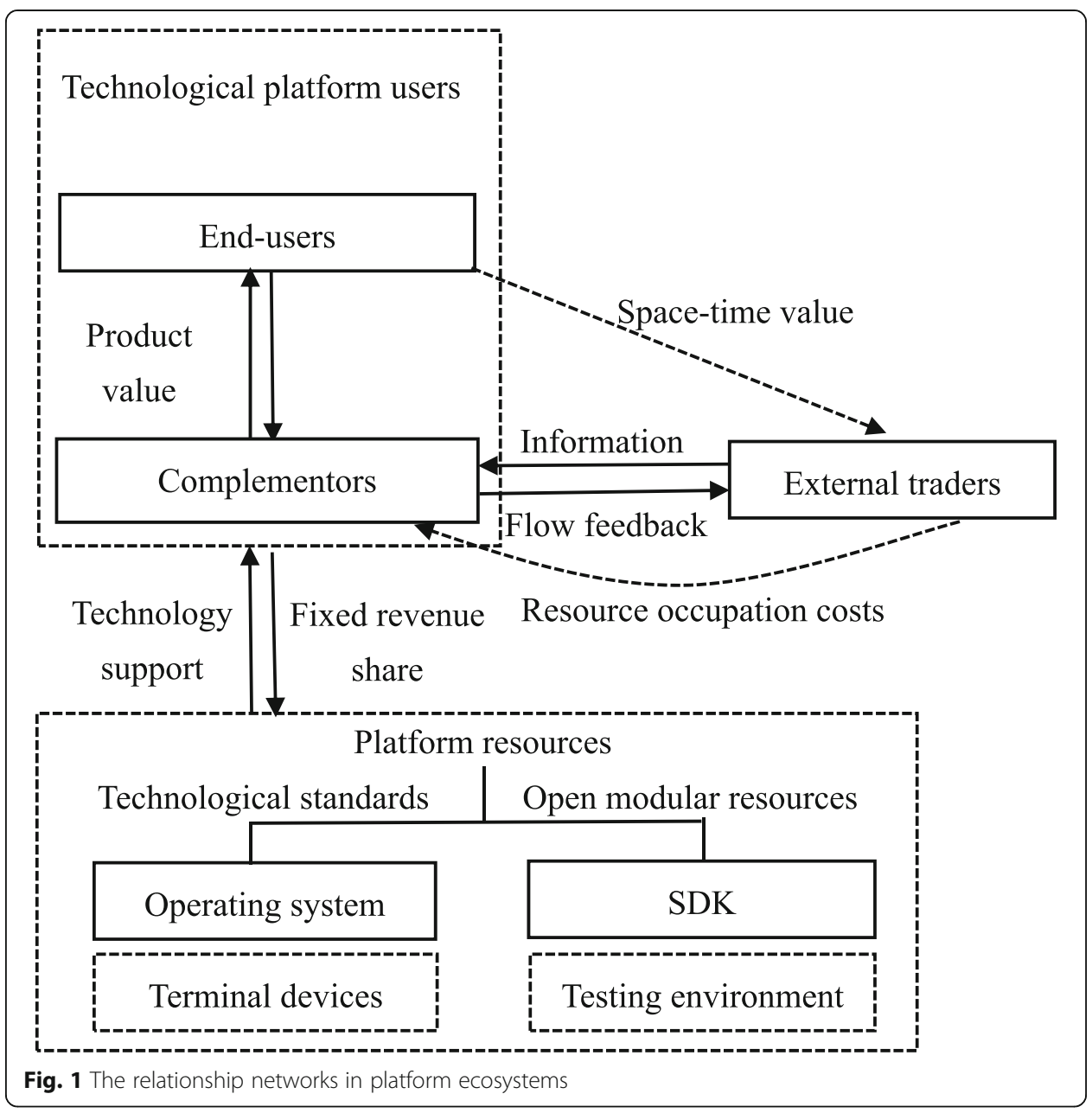

products (Min et al. 2014; Roma et al. 2016). Hence, end-users on strictly regulated platforms have higher brand loyalty and are willing to pay more for their chosen products than those on weakly regulated platforms. Ascribing the difference in assessment of digital products' time and monetary value, complementors on strictly regulated platforms tend to unearth end-users' potential value while those on weakly regulated platforms tend to benefit directly from the installed base by cooperating with external traders. Therefore, we hypothesize that:

Hypothesis 2: The strategy of in-app purchases enables complementors of free digital products on strictly regulated platforms to perform better than those on weakly regulated platforms.

\section{The heterogeneity in the supplier group}

Depending on direct/indirect network effects, a growth in the size and purchasing power of end-users will affect the growth in the number of developers positively (McIntyre and Srinivasan 2017). The intense competition among platform complementors can lead to technology spillovers as well as crowding out inferior developers. It can also stimulate leaders to update their technologies more frequently and thus drive the learning motives of imitators in the supplier group. During this process, less 
competitive developers will be crowded out and it may make competitive developers keener to improve their performance.

The competition levels of free digital products are mainly driven by differentiation of functions and services. The heterogeneity in the supplier group results from the differentiated governance rules of technological platforms. Table 1 displays the differentiated review guidelines of new applications on Apple's App Store and Google Play. Apple's App Store expels potential imitators by raising innovation barriers of entry. In fact, Apple's App Store developers introduce more differentiated applications under the same subcategory. Although Google Play publishes application distribution rules to protect intellectual property rights, many infringing applications in disguise can enter the market by exploiting gaps in the automated review process.

Technological platforms establish technology standards based on the layered modularized architecture of information integration. The open modular resources owned by platform enterprises help the participants on the supply side customize the functions of their digital products and hence determine the competition order (Kazan et al. 2018; van Alstyne et al. 2016). Platform enterprises can enhance the trust among participants by implementing effective governance (e.g., the protection of intellectual property). In this way, platform complementors are motivated to create more valuable intellectual property. As a result, the competitive edge of the platform ecosystem can be significantly strengthened (Nambisan 2013; van Alstyne et al. 2016). As for less innovative complementors on weakly regulated platforms, they can imitate leading innovators at low cost and thus weaken the positive externalities induced by product differentiation. In contrast, more innovative complementors on strictly regulated platforms can leverage positive externalities much better due to the effective protection of intellectual property. Therefore, we hypothesize that:

Hypothesis 3: An increase in the degree of product differentiation on the supply side enables complementors of free digital products on strictly regulated platforms to perform better than those on weakly regulated platforms.

\section{Methodology}

\section{Data}

In order to track the performance of free digital products and the characteristics of complementors on strictly and weakly regulated platforms, we select samples from the

Table 1 Review guidelines for new applications on Apple's App Store and Google Play

\begin{tabular}{|c|c|c|}
\hline Guideline & Apple's App Store & Google Play \\
\hline Mechanism & Mainly ex ante review & Mainly ex post review \\
\hline Ex ante review method & Manual review & $\begin{array}{l}\text { Automated review } \\
\text { (Randomly by manual review) }\end{array}$ \\
\hline Ex post review method & Consumer complaints & Consumer complaints \\
\hline Time period & 1-4 Weeks & 1-2 Days \\
\hline Focus & $\begin{array}{l}\text { The design of application icons } \\
\text { and interfaces; } \\
\text { copyright of functions; } \\
\text { ad-Placement, payment and } \\
\text { log-in compliance; } \\
\text { content validity and ratings }\end{array}$ & Content validity and ratings \\
\hline The features of approved applications & $\begin{array}{l}\text { Simple to operate; } \\
\text { elegant design; } \\
\text { creative functions }\end{array}$ & $\begin{array}{l}\text { No obvious illegal content } \\
\text { revealed by scans }\end{array}$ \\
\hline
\end{tabular}


mobile application industry. We have acquired a proprietary dataset which accounts for over $90 \%$ of the downloads and revenue earned by the iOS applications (on Apple's App Store) and Android applications (on Google Play), in the Health \& Fitness category to establish our research sample. The dataset provides us with detailed information about the applications' daily downloads, revenues and rankings. The time period is from October 2014 to December 2015. In order to assure the reliability of the data, we randomly picked 50 applications and compare the information with the data obtained from two different channels. There are no noticeable differences between the datasets. To account for left-censored issues in our data, we focus on all applications launched in the last quarter of 2014.

In addition, we employ several Java programs to transform the mobile application daily data into monthly data, and hence establish the panel data which includes the mobile application rankings, developer information, downloads and revenues. The developer-level and platform-level data in our sample are derived from three application search engines (App Annie, Apptopia and Sensor Tower), including the size, in-app purchase choices, experience level of the application developer and update frequencies of those applications. Our final sample consists of 118 free mobile applications on Apple's App Store and 48 free mobile applications on Google Play.

\section{Variables and measures \\ Dependent variable}

Our dependent variable is the logarithm of monthly total revenue earned by free mobile applications. Free mobile application publishers can obtain revenues from in-app purchases or external traders through in-app ads, online activities or data collection.

\section{Independent variables}

Since platforms are heterogeneous in our theoretical framework, we set a platform-level dummy variable store to distinguish the mobile applications on Apple's App Store and Google Play, which equals to one for the applications on Apple's App Store and zero otherwise. Platforms are described as strictly regulated and weakly regulated. We define Apple's App Store as the strictly regulated platform in line with its control system and treat Google Play as the weakly regulated platform due to its openness and weak supervision.

\section{Moderators}

We set the dummy variable in-app to measure whether the developer chooses to use an in-app purchase strategy or not, which equals to one for adopting the in-app purchase strategy and zero otherwise (Roma et al. 2016). It is the first moderator used to test Hypothesis 2, and we also observe the interaction term between in-app and store. We use the Herfindahl-Hirschman Index $(H H I)$ as the second moderator to test Hypothesis 3. According to previous research (e.g., Nelson and Winter 1982; Winter et al. 2003), the increase in the degree of product differentiation will weaken the competition intensity in a market segment. Thus we use $H H I$ to proxy the degree of product differentiation in a market segment on the two platforms where an increase in $H H I$ implies an increase in product differentiation. The market share of mobile applications is 
calculated by revenue. We can also observe the interaction term between $H H I$ and store in the model.

\section{Control variables}

We control developer-level and app-level variables to account for their possible effects on our main findings.

\section{The developer-level control variables}

First of all, we control for the variable apps which indicates the number of applications that the developers published before the observed mobile application is launched on the platform. The effect of learning by doing indicates that experience matter in the technology-intensive mobile application industry. Application developers can achieve comparative advantages including technologies and "word-of-mouth" recommendation from previous experience ( $\mathrm{Li}$ et al. 2013). We also control for the type of developers. Enterprise developers have access to abundant technical and human resources and thus can comprehensively develop the functions of mobile applications. They will test and closely track the effect of such functions to satisfy the changing needs of end-users (Roma et al. 2016). We define type as a dummy variable, assigned to one for enterprise developer and zero otherwise.

\section{The app-level control variables}

Since the performance of free digital products is heavily dependent on the size of the installed base as shown in our theoretical model and existing studies (e.g., Boudreau and Jeppesen 2015; Gawer 2014), we firstly control for the variable downloads. We also control for the variable size which indicates the size of the mobile applications. All functions and interfaces of applications are saved in the storage space. In general, the larger the application size, the more functions and more complicated interfaces are embedded to meet end-users' diversified demands (Askalidis 2015; Ghose and Han 2014). In addition, we control for the variable languages that captures the different language versions. More language versions of the applications will help the application developers enlarge the size of the installed base of their own digital products across oversea markets. We also take update into account. The more frequently the developer updates its application, the more sensitive it is to end-users' demands and competitors' innovation. We present the definitions of dependent variables, independent variables, moderators and control variables in Table 2.

\section{Statistical approach}

Our empirical work intends to test whether the performance of platform complementors of mobile applications on Apple's App Store is different from those on Google Play, owing to heterogeneous platform governance strategies and technical architectures. Our model is set up as follows:

$$
\begin{aligned}
\text { total revenue }_{i t}= & \beta_{0}+\beta_{1} \text { store }+\beta_{2} \text { in-app }_{i t}+\beta_{3} \text { HHI }_{t}+\beta_{4} \text { store } \times{\text { in }-a p p_{i}}+\beta_{5} \text { store } \\
& \times H H I_{t}+B \cdot \text { App Controls } \\
\text { it } & +\Gamma \cdot \text { Developer Controls } \\
i t & +\varepsilon_{i t} .
\end{aligned}
$$

Considering that the main effect is driven by the dummy variable store, we conduct a random effect and GLS regression analysis. Before the regression analysis, we 
Table 2 The definition of variables

\begin{tabular}{|c|c|c|}
\hline Variable group & Variable & Definition \\
\hline Dependent variable & total revenue & The logarithmic form of monthly total revenue \\
\hline Independent variable & store & $=1$ if the application is published on Apple's App Store; $=0$ otherwise \\
\hline \multirow[t]{2}{*}{ Moderators } & in-app & $=1$ if the developer adopts in-app purchase strategy; $=0$ otherwise \\
\hline & $H H I$ & The Herfindahl-Hirschman Index multiplied by 10,000 \\
\hline \multirow[t]{6}{*}{ Control variable } & apps & $\begin{array}{l}\text { The logarithmic form of the number of applications the same developer } \\
\text { has previously published }\end{array}$ \\
\hline & type & $\begin{array}{l}=1 \text { if the application is published by an enterprise developer; }=0 \\
\text { otherwise }\end{array}$ \\
\hline & downloads & The logarithmic form of monthly downloads \\
\hline & size & The logarithmic form of app size in MB \\
\hline & languages & $\begin{array}{l}\text { The logarithmic form of the number of language versions of the } \\
\text { application }\end{array}$ \\
\hline & updates & The logarithmic form of the monthly number of accumulated updates \\
\hline
\end{tabular}

implement the PSM method to select comparable mobile applications on the two heterogeneous platforms to account for sample selection bias. The first issue to address is how developers determine the choice of publishing platforms for their digital products. The single-homing (publishing their applications on a single platform) and multihoming choice of developers are likely driven by their marketing strategies, technical capabilities and prior experience.

To account for the self-selection of mobile application developers, we exploit propensity scores to match samples on the two platforms (Hirano and Imbens 2004; Rosenbaum and Rubin 1985). We choose the variables, in-app, apps, type, downloads, size, languages and updates which account for the business model and characteristics of applications to calculate the propensity scores. Then we use the matched samples to conduct the GLS regressions.

According to the principle of matching, we set mobile applications on Google Play as the control group and those on Apple's App Store as the treatment group. We adopt a Nearest Neighbor Matching (NNM) method with calipers to match samples as recommended by Abadie et al. (2004). After calculation, we define the caliper scope as 0.06 , and then match the samples where the propensity score difference is less than $6 \%$. The results for treatment effect are shown in Table 3.

Next, we continue to test whether the data is well balanced. The results in Table 4 show that the bias degree of most variables decreases significantly. Additionally, the $p$-value of most variables suggest that the matched samples do not reject the null hypothesis that there are no significant differences between samples in the treatment group and control group.

Table 3 Nearest neighbor matching by caliper results

\begin{tabular}{llllllr}
\hline Variable & Sample & Treated & Controls & Difference & S.E. & T-stat \\
\hline Total revenue & Unmatched & 2.327 & 3.932 & -1.606 & 0.157 & -10.23 \\
& ATT & 2.187 & 4.390 & -2.203 & 0.238 & -9.27 \\
& ATU & 4.189 & 1.474 & -2.715 & & \\
& ATE & & & -2.346 & & \\
\hline
\end{tabular}


Table 4 Effect of matching variables

\begin{tabular}{|c|c|c|c|c|c|c|c|c|c|c|}
\hline \multirow[t]{2}{*}{ Variable } & \multicolumn{5}{|c|}{ Unmatched } & \multicolumn{5}{|l|}{ Matched } \\
\hline & Treated & Controls & T-stat & $p>|t|$ & \%Bias & Treated & Controls & T-stat & $p>|t|$ & \%Bias \\
\hline in-app & 0.3920 & 0.2504 & 6.5700 & 0.000 & 30.7000 & 0.3638 & 0.3529 & 0.6100 & 0.542 & 2.4000 \\
\hline apps & 1.1541 & 1.2111 & -0.9100 & 0.363 & -4.2000 & 1.1707 & 1.3467 & -3.2100 & 0.001 & -13.1000 \\
\hline type & 0.8144 & 0.9585 & -9.1600 & 0.000 & -46.6000 & 0.8760 & 0.9024 & -2.2700 & 0.024 & -8.6000 \\
\hline downloads & 8.2146 & 6.9914 & 8.6400 & 0.000 & 35.7000 & 8.254 & 8.3810 & -1.1600 & 0.247 & -3.7000 \\
\hline size & 3.1335 & 2.4609 & 14.1800 & 0.000 & 65.7000 & 2.9809 & 3.0013 & -0.5700 & 0.570 & -2.0000 \\
\hline languages & 1.2546 & 1.2682 & -0.3500 & 0.724 & -1.6000 & 1.2845 & 1.3313 & -1.4700 & 0.141 & -5.5000 \\
\hline updates & 1.0991 & 1.5251 & -11.3300 & 0.000 & -52.6000 & 1.2067 & 1.2165 & -0.3700 & 0.715 & -1.2000 \\
\hline
\end{tabular}

After matching the samples, we only lose 114 observations in the control group and 238 observations in the treatment group. More than $85 \%$ of the observations are kept in the dataset. The descriptive statistics of unmatched and matched samples on the two platforms are shown in Table 5.

Table 6 reports the Pearson correlation matrix of the variables. The matrix shows that there is weak correlation between any two variables apart from $H H I$ and store. The market structure of platform complementors is likely driven by the technical architectures as expected.

\section{Results}

Main results

We conduct GLS regression on the matched samples. Table 7 shows the results of the hierarchical regression.

The results for the control variables are shown in Model 1. We find statistically significant effects of the experience, type, size, and updating speed of matched applications on their performance.

To test Hypothesis 1, we establish Model 2 by adding the dummy variable store. The results support Hypothesis 1. Compared to that complementors of free applications on Google Play, the revenue earned by complementors on Apple's App Store is lower by $252.9 \%$. The results also show that product performance of complementors on strictly regulated platforms is indeed different from that on weakly regulated platforms. This is likely due to different business models implied by platform governance. After adding the two moderators in Model 3, we find that the in-app purchase strategy and the degree of product differentiation significantly influence the product performance of complementors.

To test Hypothesis 2, we establish Model 4 by adding the interaction term between the in-app purchase strategy and store dummy. We find a positive and significant effect $(p=0.013)$, supporting Hypothesis 2. Given the strict developer selection process guided by Apple's App Store, the qualified free mobile applications on the platform can attract highly valued end-users. The platform complementors on Apple's App Store can develop innovative and high-quality mobile applications to extract consumer surplus depending on the closed technology chain and technical architectures of the platform.

To test Hypothesis 3, we establish Model 5 by adding the interaction term between market concentration and store dummy. We also find a positive and significant effect 


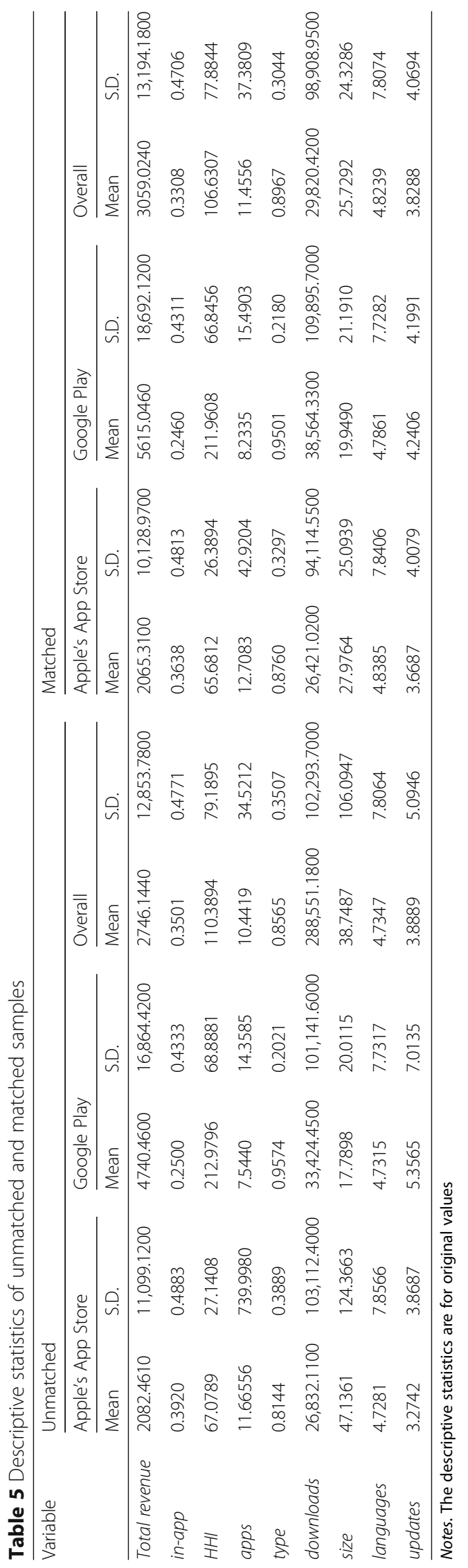


Table 6 Correlation matrix

\begin{tabular}{|c|c|c|c|c|c|c|c|c|c|}
\hline Variable & $(1)$ & (2) & (3) & (4) & $(5)$ & $(6)$ & (7) & (8) & (9) \\
\hline \multicolumn{10}{|l|}{ (1) total revenue } \\
\hline (2) store & $-0.2519^{c}$ & & & & & & & & \\
\hline (3) in-app & $0.4468^{c}$ & $0.1124^{c}$ & & & & & & & \\
\hline (4) $\mathrm{HHI}$ & $0.0887^{c}$ & $-0.8434^{c}$ & $-0.0984^{c}$ & & & & & & \\
\hline (5) apps & $0.1132^{c}$ & -0.0157 & 0.0072 & 0.0139 & & & & & \\
\hline (6) type & $0.0948^{c}$ & $-0.1094^{c}$ & $-0.1586^{c}$ & $0.0975^{c}$ & 0.0146 & & & & \\
\hline (7) downloads & $0.3592^{c}$ & $0.0725^{c}$ & -0.0103 & $-0.2023^{c}$ & $0.0374^{\mathrm{a}}$ & $0.1388^{c}$ & & & \\
\hline (8) size & $0.2012^{c}$ & $0.1884^{c}$ & $0.2721^{c}$ & $-0.1725^{c}$ & $-0.0374^{a}$ & $0.2042^{c}$ & $0.1798^{c}$ & & \\
\hline (9) languages & $0.0984^{c}$ & 0.0156 & $-0.0399^{a}$ & -0.0134 & $0.1239^{c}$ & -0.012 & $0.2223^{c}$ & $0.107^{c}$ & \\
\hline (10) updates & $0.2236^{c}$ & $-0.1136^{c}$ & $0.0872^{c}$ & $-0.0827^{c}$ & $-0.1811^{c}$ & $0.0699^{c}$ & $0.4228^{c}$ & $0.341^{c}$ & $0.0438^{b}$ \\
\hline
\end{tabular}

Notes. ${ }^{\mathrm{a}}, \mathrm{b}, \mathrm{c}$ indicate statistical significance at the $10 \%, 5 \%$ and $1 \%$ levels, respectively (using a two-tailed test)

$(p=0.000)$, supporting Hypothesis 3. The results demonstrate that application developers are capable of meeting consumers' demands by engaging in diversified competition on Apple's App Store. Application developers may develop a better self-control system under strict governance and compete efficiently with rivals.

Moreover, we add all variables and interaction terms in Model 6 and find that all coefficients of independent variables and interaction terms are qualitatively consistent.

Table 7 Platform governance and product performance of complementors

\begin{tabular}{|c|c|c|c|c|c|c|}
\hline Variable & Model 1 & Model 2 & Model 3 & Model 4 & Model 5 & Model 6 \\
\hline store & & $\begin{array}{l}-2.5292^{c} \\
(0.4539)\end{array}$ & $\begin{array}{l}-5.6659^{c} \\
(0.7375)\end{array}$ & $\begin{array}{l}-6.2177^{c} \\
(0.8012)\end{array}$ & $\begin{array}{l}-7.0368^{c} \\
(1.0393)\end{array}$ & $\begin{array}{l}-7.5564^{c} \\
(1.0924)\end{array}$ \\
\hline in-app & & & $\begin{array}{l}3.6803^{c} \\
(0.4064)\end{array}$ & $\begin{array}{l}2.2606^{c} \\
(0.6306)\end{array}$ & $\begin{array}{l}3.7159^{c} \\
(0.3997)\end{array}$ & $\begin{array}{l}2.3577^{c} \\
(0.6007)\end{array}$ \\
\hline$H H I$ & & & $\begin{array}{l}-0.0194^{c} \\
(0.0031)\end{array}$ & $\begin{array}{l}-0.0194^{c} \\
(0.0031)\end{array}$ & $\begin{array}{l}-0.0220^{c} \\
(0.0036)\end{array}$ & $\begin{array}{l}-0.0221^{c} \\
(0.0035)\end{array}$ \\
\hline in-app $\times$ store & & & & $\begin{array}{l}1.8504^{b} \\
(0.7371)\end{array}$ & & $\begin{array}{l}1.7696^{b} \\
(0.7114)\end{array}$ \\
\hline$H H I \times$ store & & & & & $\begin{array}{l}0.0154^{c} \\
(0.0046)\end{array}$ & $\begin{array}{l}0.0153^{b} \\
(0.0046)\end{array}$ \\
\hline apps & $\begin{array}{l}0.2769^{a} \\
(0.1539)\end{array}$ & $\begin{array}{l}0.2748^{a} \\
(0.1425)\end{array}$ & $\begin{array}{l}0.1614 \\
(0.1180)\end{array}$ & $\begin{array}{l}0.1325 \\
(0.1210)\end{array}$ & $\begin{array}{l}0.1759 \\
(0.1133)\end{array}$ & $\begin{array}{l}0.1481 \\
(0.1163)\end{array}$ \\
\hline type & $\begin{array}{l}0.4935 \\
(0.5130)\end{array}$ & $\begin{array}{l}-0.2174 \\
(0.5023)\end{array}$ & $\begin{array}{l}0.9814^{c} \\
(0.4511)\end{array}$ & $\begin{array}{l}0.9985^{b} \\
(0.4405)\end{array}$ & $\begin{array}{l}0.9847^{b} \\
(0.4298)\end{array}$ & $\begin{array}{l}1.0001^{b} \\
(0.4211)\end{array}$ \\
\hline downloads & $\begin{array}{l}0.3100^{c} \\
(0.0437)\end{array}$ & $\begin{array}{l}0.3210^{c} \\
(0.0439)\end{array}$ & $\begin{array}{l}0.2715^{c} \\
(0.0422)\end{array}$ & $\begin{array}{l}0.2660^{c} \\
(0.0416)\end{array}$ & $\begin{array}{l}0.3004^{c} \\
(0.0428)\end{array}$ & $\begin{array}{l}0.2951^{c} \\
(0.0419)\end{array}$ \\
\hline size & $\begin{array}{l}0.5501^{b} \\
(0.2331)\end{array}$ & $\begin{array}{l}0.8826^{c} \\
(0.2209)\end{array}$ & $\begin{array}{l}0.4797^{c} \\
(0.1782)\end{array}$ & $\begin{array}{l}0.5170^{c} \\
(0.1803)\end{array}$ & $\begin{array}{l}0.4072^{b} \\
(0.1743)\end{array}$ & $\begin{array}{l}0.4433^{c} \\
(0.1764)\end{array}$ \\
\hline languages & $\begin{array}{l}0.0667 \\
(0.2821)\end{array}$ & $\begin{array}{l}0.0383 \\
(0.2690)\end{array}$ & $\begin{array}{l}0.2276 \\
(0.2191)\end{array}$ & $\begin{array}{l}0.2462 \\
(0.2160)\end{array}$ & $\begin{array}{l}0.2133 \\
(0.2107)\end{array}$ & $\begin{array}{l}0.2311 \\
(0.2084)\end{array}$ \\
\hline updates & $\begin{array}{l}-0.0330 \\
(0.1762)\end{array}$ & $\begin{array}{l}-0.773 \\
(0.1741)\end{array}$ & $\begin{array}{l}-0.7844^{c} \\
(0.1624)\end{array}$ & $\begin{array}{l}-0.7825^{c} \\
(0.1608)\end{array}$ & $\begin{array}{l}-0.5840^{c} \\
(0.1628)\end{array}$ & $\begin{array}{l}-0.5833^{\circ} \\
(0.1614)\end{array}$ \\
\hline Constant & $\begin{array}{l}-2.1003 \\
(0.8713)\end{array}$ & $\begin{array}{l}-0.6332 \\
(0.9088)\end{array}$ & $\begin{array}{l}3.7485^{c} \\
(1.1619)\end{array}$ & $\begin{array}{l}4.0695^{c} \\
(1.1526)\end{array}$ & $\begin{array}{l}4.0085^{c} \\
(1.1857)\end{array}$ & $\begin{array}{l}4.3133^{b} \\
(1.1795)\end{array}$ \\
\hline $\mathrm{N}$ & 2004 & 2004 & 2004 & 2004 & 2004 & 2004 \\
\hline
\end{tabular}

Notes. The values in brackets indicate the standard error of the estimated coefficient. ${ }^{\mathrm{a}}{ }^{\mathrm{b}} \mathrm{c}$ indicate statistical significance at the $10 \%, 5 \%$ and $1 \%$ levels, respectively 


\section{Robustness tests}

To assure our estimates are robust to any potential sampling bias, we use the unmatched full samples and multi-homing samples to run regressions. The unmatched full samples are likely to account for heterogeneous free mobile applications while the multi-homing samples consider the same free mobile applications in the two platforms. We can test whether platform governance will still exert different impacts on product performance of complementors in the two platforms. Even if only a small proportion of the developers published their applications on the two platforms, we can compare the characteristics and performance of those applications on the two platforms. Table 8 reports the results by conducting random effect regressions. The results are consistent with the results of Model 6 in Table 7.

\section{Discussion and conclusion}

Using a dataset of mobile applications from Apple's App Store and Google Play, we find that different platform governance strategies shape differentiated market structures and complementors' product performance through direct/indirect network effects. Our study leverages the perspective of platform ecosystems to analyze the interactions among platform enterprises, complementors and end-users within heterogeneous platform ecosystems and their effects on complementors' product performance.

Table 8 Robustness tests using unmatched samples

\begin{tabular}{|c|c|c|}
\hline \multirow[t]{2}{*}{ Variable } & Model 7 & Model 8 \\
\hline & Full samples & Multi-homing samples \\
\hline store & $\begin{array}{l}-6.9284^{c} \\
(0.9958)\end{array}$ & $\begin{array}{l}-5.9248^{b} \\
(1.8819)\end{array}$ \\
\hline in-app & $\begin{array}{l}2.2083^{c} \\
(0.5961)\end{array}$ & $\begin{array}{l}2.8909^{c} \\
(0.9802)\end{array}$ \\
\hline$H H I$ & $\begin{array}{l}-0.0200^{c} \\
(0.0033)\end{array}$ & $\begin{array}{l}-0.0129^{b} \\
(0.0054)\end{array}$ \\
\hline in-app $\times$ store & $\begin{array}{l}1.6115^{b} \\
(0.6979)\end{array}$ & $\begin{array}{l}2.2888^{a} \\
(1.2729)\end{array}$ \\
\hline$H H I \times$ store & $\begin{array}{l}0.0120^{c} \\
(0.0044)\end{array}$ & $\begin{array}{l}0.0135 \\
(0.0093)\end{array}$ \\
\hline apps & $\begin{array}{l}0.1502 \\
(0.1126)\end{array}$ & $\begin{array}{l}0.0390 \\
(0.3582)\end{array}$ \\
\hline type & $\begin{array}{l}0.8235^{b} \\
(0.3928)\end{array}$ & $\begin{array}{l}0.5985 \\
(0.4331)\end{array}$ \\
\hline downloads & $\begin{array}{l}0.3250^{c} \\
(0.0645)\end{array}$ & $\begin{array}{l}0.3193^{c} \\
(0.1110)\end{array}$ \\
\hline size & $\begin{array}{l}0.3058^{a} \\
(0.1570)\end{array}$ & $\begin{array}{l}0.1710 \\
(0.4201)\end{array}$ \\
\hline languages & $\begin{array}{l}0.1700 \\
(0.2051)\end{array}$ & $\begin{array}{l}-0.0239 \\
(0.3193)\end{array}$ \\
\hline updates & $\begin{array}{l}-0.5951^{c} \\
(0.1522)\end{array}$ & $\begin{array}{l}-0.4850^{b} \\
(0.2269)\end{array}$ \\
\hline constant & $\begin{array}{l}4.2433^{c} \\
(1.0890)\end{array}$ & $\begin{array}{l}3.4701^{b} \\
(1.4950)\end{array}$ \\
\hline $\mathrm{N}$ & 2356 & 477 \\
\hline
\end{tabular}

Notes. The values in brackets indicate the standard error of the estimated coefficient. ${ }^{\mathrm{a}}, \mathrm{b}, \mathrm{c}$ indicate statistical significance at the $10 \%, 5 \%$ and $1 \%$ levels, respectively 


\section{Theoretical implications}

Our study contributes to research on platform ecosystems, platform governance, and complementors' business strategies. First, our study of Apple's App Store and Google Play shows that platform ecosystems based on differentiated technical architectures can align interdependent participants to exchange, co-create, and enhance value and enable them to consistently benefit from positive network externalities. The study integrates the perspective of network externalities based on two-sided market theory with the perspective of platform ecosystems, and thus illustrates how network externalities and value co-creation drive the growth of the whole platform ecosystem.

Second, platform enterprises play an important role in the process of matching supply with demand within the platform ecosystem through appropriate governance strategies. Apple's App Store, the proprietary platform, regulates the platform system strictly and complementors are motivated to innovate and satisfy the needs of endconsumers by providing high-quality products/services. In contrast, Google Play, the open resource platform, regulates the platform system flexibly and complementors can enlarge the size of the installed base benefitting from cooperation with external traders (e.g., advertisement revenue). Thus, under an oligopolistic market structure, platform enterprises are expected to have effective governance strategies to guide complementor behavior and improve the competition efficiency within the ecosystem.

Third, platform heterogeneity arises from different governance strategies, which has significant implications for complementors in implementing different business strategies. Our study shows that complementors on Apple's App Store and Google Play design different business models to respond to platform governance strategies by leveraging direct/indirect network effects more efficiently. Embedded in the platformmediated networks, complementors adopt differentiated business strategies to cooperate with external traders in line with consumer preferences to create more value and thus cultivate a benign cycle among all ecosystem participants.

\section{Managerial implications}

Our study also yields insights into business practices. As an important form of industry organization, platform enterprises are indispensable intermediaries in our daily lives. However, quality and safety issues emerge from the lack of effective platform governance (i.e., in Google Play). Platform enterprises should set feasible technology standards and entry barriers to promote diversified competition among complementors, which will also benefit the growth of the whole platform ecosystem. Effective platform governance forces platform complementors to focus on the latest technical developments and end-users' demands and thus improve product quality. The complementors are therefore more capable of integrating and updating resources to compete efficiently with rivals.

Our study also has implications for different business models and complementors' product performance on heterogeneous platforms. The business models of free digital products are heavily reliant upon the size of the installed base. The size effect of the consumer group on Google Play is larger than that for Apple's App Store. However, consumers on Apple's App Store are more willing to pay high prices for quality products/services because Apple's App Store has established a unique brand reputation and high technical standards. The competition on the supplier side tends to be more 
intensive owing to high consumer surplus and high entry barriers on Apple's App Store. Thus, complementors need to invest more in research and development to establish customer loyalty on Apple's App Store. Due to positive network externalities, complementor-leading innovations are likely to be beneficial for the whole platform ecosystem.

\section{Limitations and future research}

Our study entails several limitations to be addressed by further research. We classify technological industry platforms into two groups, weakly regulated platforms and strictly regulated platforms in line with open/closed operating systems. Although our study illustrates differentiated governance strategies on two heterogeneous platforms in this context, future research may explore more ways to investigate platform heterogeneity by leveraging the perspective of platform ecosystems and assess the effectiveness of governance strategies in more complex contexts. Additionally, due to the availability of data, our sample is limited to one category, Health \& Fitness, on Apple's App Store and Google Play. In the future, samples from more categories of mobile applications or other digital platforms can be used to test the generalizability of our study.

\section{Endnotes}

${ }^{1}$ The term "network externalities" mentioned in Armstrong (2006) and Rochet and Tirole (2006) is also widely expressed as "network effects" including direct network effects and indirect network effects (cross-group network externalities) in later literature (e.g., Adner and Kapoor 2010; Eisenmann et al. 2006; Gawer and Henderson 2007; Gawer 2014 etc.).

${ }^{2}$ For example, individual developers and enterprise developers on Apple's App Store are charged \$99 a year to publish their applications. All types developers on Google Play are charged $\$ 25$, which is valid for life. In 2016, both platforms shifted their share of developers' total revenue from $30 \%$ to $15 \%$.

${ }^{3}$ See: "Gartner says mobile app stores will see annual downloads reach 102 billion in 2013" http://www.gartner.com/newsroom/id/2592315.

${ }^{4}$ Two-part tariff is the mainstream pricing strategy of free digital products on technological platforms. End-users need not pay for getting access to the digital product while they have to pay when they want to use certain function embedded in the product (Oi 1971). For example, video and audio websites such as NetEase Cloud Music and QQ Music offer free trials for music but audiences still need to pay when they want to download.

\section{Acknowledgements}

This study was funded by the National Natural Science Foundation of China (Grant No. 71873136).

\section{Authors' contributions}

JY conceived of the study, and participated in its design and coordination and helped to draft the manuscript. JH participated in the design of the study, performed the statistical analysis, and drafted the manuscript. LY participated in the design of the study and helped to draft the manuscript, All authors read and approved the final manuscript.

Funding

This study was funded by the National Natural Science Foundation of China (Grant No. 71873136). 


\section{Author details}

'Business School, Renmin University of China, Beijing 100872, China. ${ }^{2}$ Institute of Urban Development, Nanjing Audit University, Nanjing 211815, China.

Received: 25 October 2018 Accepted: 11 June 2019

\section{Published online: 15 August 2019}

\section{References}

Abadie, A., Drukker, D., Herr, J. L., \& Imbens, G. W. (2004). Implementing matching estimators for average treatment effects in Stata. The Stata Journal, 4(3), 290-311.

Adner, R., \& Kapoor, R. (2010). Value creation in innovation ecosystems: How the structure of technological interdependence affects firm performance in new technology generations. Strategic Management Journal, 31(3), 306-333.

Anderson, S. P., \& Coate, S. (2005). Market provision of broadcasting: A welfare analysis. The Review of Economic Studies, 72(4), 947-972.

Armstrong, M. (2006). Competition in two-sided markets. The Rand Journal of Economics, 37(3), 668-691.

Askalidis, G. (2015). The impact of large scale promotions on the sales and ratings of mobile apps: Evidence from Apple's app store arXiv preprint arXiv:1506.06857.

Benlian, A., Hilkert, D., \& Hess, T. (2015). How open is this platform? The meaning and measurement of platform openness from the complementors' perspective. Journal of Information Technology, 30(3), 209-228.

Bhargava, H. K., \& Choudhary, V. (2008). Research note-When is versioning optimal for information goods? Management Science, 54(5), 1029-1035.

Boudreau, K. J. (2010). Open platform strategies and innovation: Granting access vs. devolving control. Management Science, 56(10), 1849-1872.

Boudreau, K. J., \& Jeppesen, L. B. (2015). Unpaid crowd complementors: The platform network effect mirage. Strategic Management Journal, 36(12), 1761-1777.

Caillaud, B., \& Jullien, B. (2003). Chicken \& egg: competition among intermediation service providers. RAND Journal of Economics, 34(2), 309-328.

Carare, O. (2012). The impact of bestseller rank on demand: evidence from the app market. International Economic Review, 53(3), 717-742

Ceccagnoli, M., Forman, C., Huang, P., \& Wu, D. J. (2012). Cocreation of value in a platform ecosystem! The case of enterprise software. MIS Quarterly, 36(1), 263-290.

Cennamo, C., \& Santalo, J. (2013). Platform competition: strategic trade-offs in platform markets. Strategic Management Journal, 34(11), 1331-1350.

Cheng, H. K., \& Liu, Y. (2012). Optimal software free trial strategy: The impact of network externalities and consumer uncertainty. Information Systems Research, 23(2), 488-504.

Economides, N., \& Katsamakas, E. (2006). Two-sided competition of proprietary vs. open source technology platforms and the implications for the software industry. Management Science, 52(7), 1057-1071.

Eisenmann, T., Parker, G., \& van Alstyne, M. W. (2006). Strategies for Two Sided Markets. Harvard Business Review, 84(10), 92-101.

Eisenmann, T., Parker, G., \& van Alstyne, M. W. (2011). Platform envelopment. Strategic Management Journal, 32(12), $1270-1285$.

Feng, H., \& Chen, Y. Q. (2016). Research on platform business model innovation-based on a time-spatial correspond analysis under internet environment. China Industrial Economics, 16(3), 99-113.

Garg, R., \& Telang, R. (2013). Inferring app demand from publicly available data. MIS Quarterly, 37(4), 1253-1264.

Gawer, A. (2014). Bridging differing perspectives on technological platforms: Toward an integrative framework. Research Policy, 43(7), 1239-1249.

Gawer, A., \& Cusumano, M. A. (2014). Industry platforms and ecosystem innovation. Journal of Product Innovation Management, 31(3), 417-433.

Gawer, A., \& Henderson, R. (2007). Platform owner entry and innovation in complementary markets: Evidence from Intel. Journal of Economics \& Management Strategy, 16(1), 1-34.

Ghazawneh, A., \& Henfridsson, O. (2013). Balancing platform control and external contribution in third-party development: The boundary resources model. Information Systems Journal, 23(2), 173-192.

Ghose, A., \& Han, S. P. (2014). Estimating demand for mobile applications in the new economy. Management Science, 60(6), $1470-1488$.

Hagiu, A. (2006). Pricing and commitment by two-sided platforms. The Rand Journal of Economics, 37(3), 720-737.

Hagiu, A., \& Spulber, D. (2013). First-party content and coordination in two-sided markets. Management Science, 59(4), $933-949$.

Hirano, K., \& Imbens, G. W. (2004). The propensity score with continuous treatments. In Applied Bayesian modeling and causal inference from incomplete-data perspectives: An essential journey with Donald Rubin's statistical family No. 226164.

Kapoor, R., \& Agarwal, S. (2017). Sustaining superior performance in business ecosystems: evidence from application software developers in the iOS and android smartphone ecosystems. Organization Science, 28(3), 531-551.

Kapoor, R., \& Lee, J. M. (2013). Coordinating and competing in ecosystems: How organizational forms shape new technology investments. Strategic Management Journal, 34(3), 274-296.

Katz, M. L., \& Shapiro, C. (1985). Network externalities, competition, and compatibility. American Economic Review, 75(3), 424-440.

Kazan, E., Tan, C. W., Lim, E. T., Sørensen, C., \& Damsgaard, J. (2018). Disentangling digital platform competition: The case of UK mobile payment platforms. Journal of Management Information Systems, 35(1), 180-219.

Li, M., Goh, K. Y., \& Cavusoglu, H. (2013). Mobile app portfolio management and developers' performance: An empirical study of the apple iOS platform. Agribusiness, 27(27), 360-378.

Mclntyre, D. P., \& Srinivasan, A. (2017). Networks, platforms, and strategy: Emerging views and next steps. Strategic Management Journal, 38(1), 141-160.

Min, H. R., Kim, J., \& Kim, S. (2014). Factors affecting application developers' loyalty to mobile platforms. Computers in Human Behavior, 40, 78-85. 
Nambisan, S. (2013). Information technology and product/service innovation: A brief assessment and some suggestions for future research. Journal of the Association for Information Systems, 14(4), 215-226.

Nelson, R. R., \& Winter, S. G. (1982). An evolutionary theory of economic change. Cambridge: The Belknap Press of Harvard University.

Oi, W. Y. (1971). A Disneyland dilemma: Two-part tariffs for a Mickey mouse monopoly. The Quarterly Journal of Economics, 85, $77-96$.

Parker, G. G., \& van Alstyne, M. W. (2005). Two-sided network effects: A theory of information product design. Management Science, 51(10), 1494-1504.

Parker, G. G., van Alstyne, M. W., \& Choudary, S. P. (2016). Platform revolution. New York, NY: W.W. Norton.

Rochet, J. C., \& Tirole, J. (2003). Platform competition in two-sided markets. Journal of the European Economic Association, 1(4), 990-1029.

Rochet, J. C., \& Tirole, J. (2006). Two-sided markets: A progress report. The Rand Journal of Economics, 37(3), 645-667.

Roma, P., Zambuto, F., \& Perrone, G. (2016). The role of the distribution platform in price formation of paid apps. Decision Support Systems, 91, 13-24

Rosenbaum, P. R., \& Rubin, D. B. (1985). Constructing a control group using multivariate matched sampling methods that incorporate the propensity score. The American Statistician, 39(1), 33-38.

Sheth, J. N., Newman, B. I., \& Gross, B. L. (1991). Why we buy what we buy: A theory of consumption values. Journal of Business Research, 22(2), 159-170.

Tiwana, A. (2013). Platform ecosystems: Aligning architecture, governance, and strategy. Waltham, MA: Elsevier.

Tiwana, A., Konsynski, B., \& Bush, A. A. (2010). Research commentary_Platform evolution: Coevolution of platform architecture, governance, and environmental dynamics. Information Systems Research, 21(4), 675-687.

van Alstyne, M. W., Parker, G. G., \& Choudary, S. P. (2016). Pipelines, platforms, and the new rules of strategy. Harvard Business Review, 94(4), 54-62.

Vinson, D. E., Scott, J. E., \& Lamont, L. M. (1977). The role of personal values in marketing and consumer behavior. The Journal of Marketing, $41(2), 44-50$.

West, J. (2003). How open is open enough?: Melding proprietary and open source platform strategies. Research Policy, 32(7), 1259-1285.

Weyl, E. G. (2010). A price theory of multi-sided platforms. American Economic Review, 100(4), 1642-1672.

Winter, S. G., Kaniovski, Y. M., \& Dosi, G. (2003). A baseline model of industry evolution. Journal of Evolutionary Economics, 13(4), 355-383.

Yonatany, M. (2017). Platforms, ecosystems, and the internationalization of highly digitized organizations. Journal of Organization Design, 6(1), 1-5.

\section{Publisher's Note}

Springer Nature remains neutral with regard to jurisdictional claims in published maps and institutional affiliations.

\section{Submit your manuscript to a SpringerOpen ${ }^{\circ}$ journal and benefit from:}

- Convenient online submission

Rigorous peer review

- Open access: articles freely available online

High visibility within the field

- Retaining the copyright to your article

Submit your next manuscript at $\boldsymbol{\nabla}$ springeropen.com 